\title{
LOCAL GAS HOLDUP AND GAS RECIRCULATION RATE IN AN AERATED VESSEL EQUIPPED WITH A RUSHTON TURBINE IMPELLER
}

\author{
KATSUHIDE TAKENAKA AND KoJI TAKAHASHI \\ Department of Materials Science and Engineering, Yamagata \\ University, Yonezawa 992
}

\begin{abstract}
Key Words: Agitation, Gas Liquid Mixing, Local Gas Holdup, Gas Recirculation Rate, Rushton Turbine Impeller
\end{abstract}

\begin{abstract}
Local gas holdup was measured throughout an aerated vessel equipped with a Rushton turbine impeller by means of an electrical probe. Integration of the data of local gas holdup gave a good correlation for the overall gas holdup. The gas recirculation rate, which influences cavity formation and the related power consumption and mass transfer, was also determined by integrating the data of local gas holdup for regions lower than the height of impeller. By taking into account the gas recirculation rates, a more precise correlation for overall gas holdup could be obtained.
\end{abstract}

\section{Introduction}

In the process industries, gas-liquid contacting in agitated vessels is extensively used in order for mass transfer and chemical reactions. Therefore, characteristics such as gassed power consumption, bubble size, gas holdup and gas-liquid mass transfer in a gassparged agitated vessel have been extensively investigated, and many correlations for these characteristics have been proposed by many investigators. However, a distinction still exists in these correlations. It may be due to the fact that the characteristics are dependent upon gas bubble distributions throughout the vessel and gas cavities behind the blades.

In this paper, the local gas holdup throughout the vessel was measured by means of an electrical probe. Complicated gas holdup distributions were obtained, which were almost the same as mentioned by previous investigators (Nienow et al., 1977; Nagase and Yasui, 1983). By integration of local gas holdup throughout the vessel, the correlation of overall gas holdup was derived. The recirculating gas flow rate, which influences cavity formation and the related power consumption, was also determined from the data of local gas holdup for regions lower than the height of impeller.

\section{Experiment}

\subsection{Experimental setup}

A six-blade Rushton disc turbine impeller was adopted since its gas-dispersing mechanisms have been investigated and used extensively for gas dispersion in the process industries. An open-topped

* Received on December 25, 1995. Correspondence concerning this article should be addressed to $\mathrm{K}$. Takahashi. 0.29-m diameter $(T)$ cylindrical vessel with four baffles having a width of one-tenth of the vessel diameter was used. The liquid height was equal to the vessel diameter and the impeller-to-vessel diameter ratio was 0.4. The clearance of the impeller from the tank base was set at $T / 4$. Liquid was the tap water and air was introduced through a point sparger.

Gas flow rates of $3.33 \times 10^{-5}$ to $2.50 \times 10^{-4} \mathrm{~m}^{3} \mathrm{~s}^{-1}$, i.e. 0.104 to $0.783 \mathrm{vvm}$ were used with an impeller speed of $3.33-5.00 \mathrm{~s}^{-1}$.

\subsection{Measuring points and device}

The measurement of gas holdup was conducted at the intersections of the cylindrical coordinates in a quarter of the vessel, as shown in Fig. 1, because the data must be periodical with a period of $90^{\circ}$ in circumferential direction.

Local gas holdup was measured by means of a gas-liquid two-phase flow meter system (Kanomax, system 7931) with the electrical conductivity probe. The probe can detect the difference in conductivities between gas and liquid passing through a fine pointed end made of a platinum cylinder of $100 \mu \mathrm{m}$ diameter. Figure 2 shows a schematic diagram of the pointed end of the probe and the signals detected with the relative position of the bubble. From the sum of the time duration of pulses for gas bubbles passed through the pointed end in every direction, the gas holdup at each local position could be determined.

\section{Results and Discussion}

\subsection{Local gas holdup}

Figure 3 shows the local gas holdup distributions at cross sections of several heights for different experimental conditions. As can be seen from the figure, the patterns of gas bubble dispersion in regions higher than the height of impeller are almost the same 


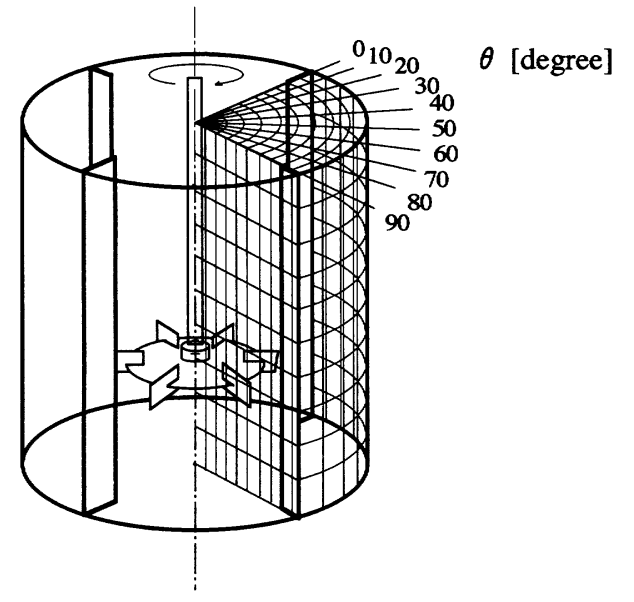

Fig. 1 Measuring points of local gas holdup

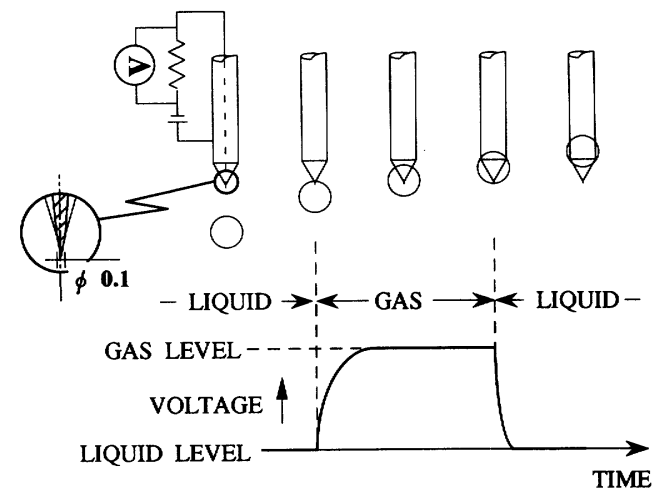

Fig. 2 Schematic diagram of pointed end of probe and signals detected
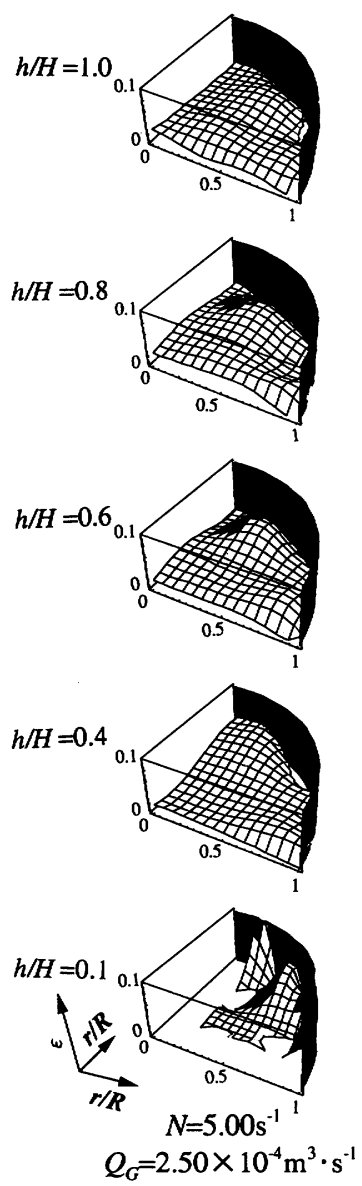
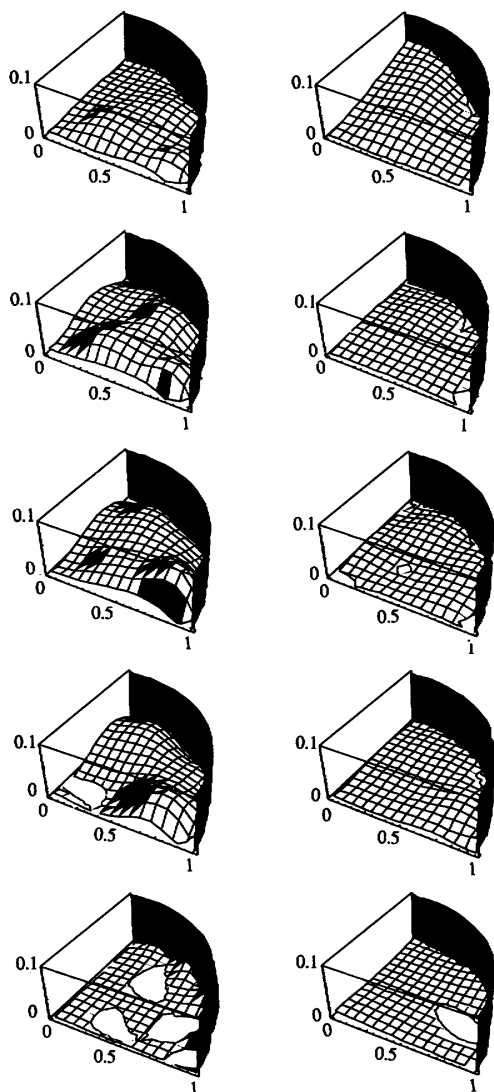

$N=3.33 \mathrm{~s}^{-1}$

$Q_{G}=2.50 \times 10^{-4} \mathrm{~m}^{3} \cdot \mathrm{s}^{-1}$

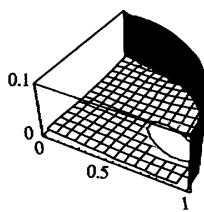

$N=5.00 \mathrm{~s}^{-1}$

$Q_{G}=3.33 \times 10^{-5} \mathrm{~m}^{3} \cdot \mathrm{s}^{-1}$

Fig. 3 Local gas holdup distributions

in spite of the different experimental conditions covered in this work. Namely, local gas holdup near the vessel wall is high, at $h / H=0.6$, and that between the shaft and vessel wall is high, at $h / H=1.0$, where data corresponding to the air above the liquid free surface were omitted. These results, which approximately correspond to those reported by several investigators
(Nienow et al., 1977; Nagase and Yasui, 1983), may be explained by considering the observed gas dispersion as shown in Fig. 4. The centers of the gross circulation vortices are regions of low velocity and high holdup with their peripheries being regions of high velocity and low holdup. On the other hand, in regions lower than the height of the impeller, local gas 


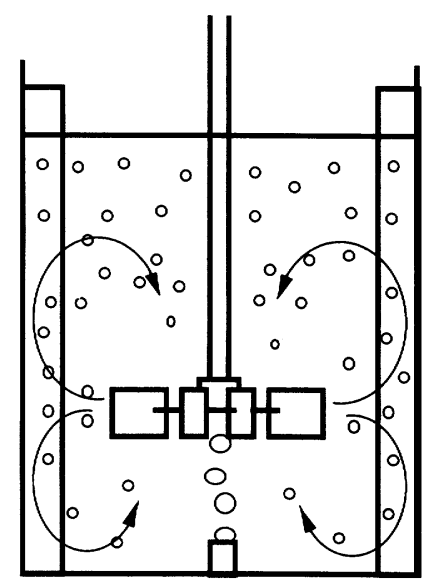

Fig. 4 Gas bubbles flow in vessel

holdup only for $N=5.00 \mathrm{~s}^{-1}$ and $Q_{G}=2.50 \times 10^{-4} \mathrm{~m}^{3} \mathrm{~s}^{-1}$ shows a high value near the vessel wall, because of the onset of small recirculation.

\subsection{Correlation of overall gas holdup}

Most published correlation for gas holdup are derived from experiments by observing the rise in level of the surface by the naked eye (Chapman et al., 1983) or by measuring using conductivity probes (Greaves and Barigou, 1988).

In this work, the overall gas holdup was determined by integrating the local gas holdup data throughout the vessel for each experimental condition and was correlated by using a multiple non-linear regression. The correlation obtained is given as follows.

$$
\varepsilon_{\text {overall }}=0.621 N^{0.21} Q_{G}^{0.437}
$$

The average deviation is $9.93 \times 10^{-3}$. Smith and Warmoeskerken (1985) correlated the gas holdup with the equations

before large cavities are formed

$$
\varepsilon_{\text {overall }}=0.62 N^{1.6} Q_{G}^{0.45}
$$

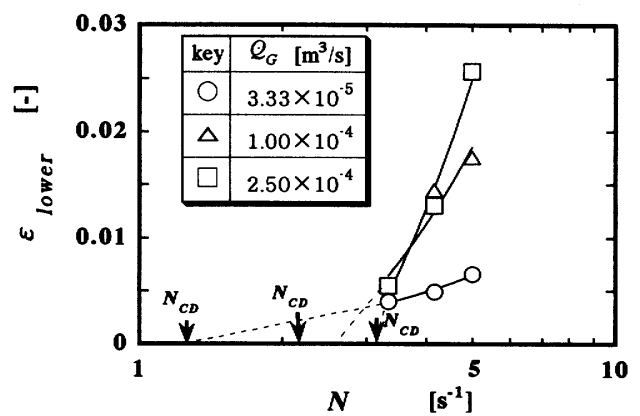

Fig. 5 Average gas holdup at lower region (arrow shows calculated value of $N_{C D}$ from Eq. (4))

and after large cavities have been formed

$$
\varepsilon_{\text {overall }}=1.67 N^{0.7} Q_{G}^{0.75}
$$

The experimental and calculated values of $\varepsilon_{\text {overall }}$ are summarized in Table 1, which shows that the data obtained in this work could not be expressed by Eqs. (2) and (3). This may be due to the difference in the measuring methods. The data obtained by the methods developed previously may include the effect of surface vibration at high impeller speed. On the other hand, it is hard for the method used in this work to measure the gas holdup in impeller and sparger regions.

An interesting information was also derived from the data of the local gas holdup in the lower region than the height of impeller. The average gas holdup at the lower region, which was calculated by integrating the local gas holdup at the regions lower than the height of impeller, is shown in Fig. 5. The solid lines displayed in Fig. 5 were those calculated by using the least-squares method. As can be seen from the figure, the gas holdup at the lower region increases with an increase in impeller speed for each gas flow rate, and the dependency of the gas holdup on impeller speed increases with an increase in gas flow rate.

\begin{tabular}{|c|c|c|c|c|c|c|}
\hline \multirow{2}{*}{$\begin{array}{c}N \\
{\left[\mathrm{~s}^{-1}\right]}\end{array}$} & \multirow{2}{*}{$\begin{array}{c}Q_{G} \\
{\left[\mathrm{~m}^{3} \mathrm{~s}^{-1}\right]}\end{array}$} & \multirow{2}{*}{ Experimental } & \multicolumn{4}{|c|}{ Calculated } \\
\hline & & & Eq. (1) & Eq. (2) & Eq. (3) & Eq. (9) \\
\hline $\left.\begin{array}{l}3.33 \\
4.17 \\
5.00\end{array}\right\}$ & $3.33 \times 10^{-5}$ & $\left\{\begin{array}{l}5.65 \times 10^{-3} \\
5.39 \times 10^{-3} \\
7.17 \times 10^{-3}\end{array}\right.$ & $\begin{array}{l}8.83 \times 10^{-3} \\
9.26 \times 10^{-3} \\
9.62 \times 10^{-3}\end{array}$ & $\begin{array}{l}4.12 \times 10^{-2} \\
5.88 \times 10^{-2} \\
7.87 \times 10^{-2}\end{array}$ & $\begin{array}{l}1.70 \times 10^{-3} \\
1.99 \times 10^{-3} \\
2.26 \times 10^{-3}\end{array}$ & $\begin{array}{l}6.55 \times 10^{-3} \\
5.84 \times 10^{-3} \\
6.30 \times 10^{-3}\end{array}$ \\
\hline $\left.\begin{array}{l}3.33 \\
4.17 \\
5.00\end{array}\right\}$ & $1.00 \times 10^{-4}$ & $\left\{\begin{array}{l}1.86 \times 10^{-2} \\
2.01 \times 10^{-2} \\
1.90 \times 10^{-2}\end{array}\right.$ & $\begin{array}{l}1.43 \times 10^{-2} \\
1.50 \times 10^{-2} \\
1.55 \times 10^{-2}\end{array}$ & $\begin{array}{l}6.73 \times 10^{-2} \\
9.65 \times 10^{-2} \\
1.29 \times 10^{-1}\end{array}$ & $\begin{array}{l}3.88 \times 10^{-3} \\
4.54 \times 10^{-3} \\
5.15 \times 10^{-3}\end{array}$ & $\begin{array}{l}1.86 \times 10^{-2} \\
1.94 \times 10^{-2} \\
1.97 \times 10^{-2}\end{array}$ \\
\hline $\left.\begin{array}{l}3.33 \\
4.17 \\
5.00\end{array}\right\}$ & $2.50 \times 10^{-4}$ & $\left\{\begin{array}{l}2.02 \times 10^{-2} \\
1.94 \times 10^{-2} \\
2.25 \times 10^{-2}\end{array}\right.$ & $\begin{array}{l}2.13 \times 10^{-2} \\
2.24 \times 10^{-2} \\
2.32 \times 10^{-2}\end{array}$ & $\begin{array}{l}1.02 \times 10^{-1} \\
1.46 \times 10^{-1} \\
1.95 \times 10^{-1}\end{array}$ & $\begin{array}{l}7.71 \times 10^{-3} \\
9.02 \times 10^{-3} \\
1.02 \times 10^{-2}\end{array}$ & $\begin{array}{l}5.19 \times 10^{-2} \\
3.87 \times 10^{-2} \\
3.71 \times 10^{-2}\end{array}$ \\
\hline
\end{tabular}

If the solid lines are extrapolated, the inter-

Table 1 Comparison of gas holdup values $\varepsilon_{\text {overall }}$ 
section with the abscissa at $\varepsilon_{\text {lower }}=0$ may correspond to the minimum speed to just completely disperse the gas throughout the whole vessel, $N_{C D}$. Nienow et al. (1977) have given the following empirical correlation for the complete dispersion condition.

$$
Q_{G} / N_{C D} D^{3}=0.2(T / D)^{0.5}\left(N_{C D}^{2} D / g\right)^{0.5}
$$

The calculated value of $N_{C D}$ for each $Q_{G}$, which fits well with the intersection of the calculated line with the abscissa, is shown in Fig. 5 .

\subsection{Estimation of recirculated gas flow rate}

The gas recirculated comes back into the cavity with freshly sparged gas and affects the gassed power and the mass transfer. The gas recirculation also depends on the bubble size and hence upon the coalescence properties of the dispersion. Therefore, it is useful to quantify the recirculated gas flow rate.

A simple method to estimate the recirculated gas flow rate from power drawn was proposed by van't Riet et al. (1976). They assumed that the recirculation was eliminated by using large vessels with very small impellers and determined the recirculated gas flow rate from the curves for the relative power consumption with and without recirculation, that is for an ordinary and a large vessel, under otherwise similar conditions. At a certain gas inflow from the sparger $Q_{G}$, power consumption with recirculation corresponds to that without recirculation for a gas inflow $Q_{T}$, because of the additional gas flow from recirculation $Q_{R}$. This is shown in Fig. 6.

In this work, estimation of the recirculated gas flow rate was tried according to this method first. A vessel of $0.24 \mathrm{~m}$ diameter $\left(T_{s}\right)$ and one of $0.98 \mathrm{~m}$ diameter $\left(T_{l}\right)$ with four baffles were used as a standard and a large vessel, respectively. The heights of the impeller above the tank base in both vessels were set at $T_{s} / 2, T_{s} / 3$ and $T_{s} / 4$. Three typical impellers used were a six-blade Rushton turbine, a flat paddle and a pitched turbine pumping downward. Power was measured by using a digital torque meter. The power curves obtained for the Rushton turbine in large and standard vessels are shown in Fig. 7 as an example. This result indicates that the value of the recirculated gas flow rate cannot be estimated by the method proposed by van't Riet et al. (1976). For the other two impellers, almost the same results were obtained. Therefore, it would be concluded that the method proposed by van't Riet et al. (1976) was not applicable to assess the recirculated gas flow rate for impellers used in this work.

From the above result, it is obvious that a new method to estimate the recirculated gas flow rate must be established. We consider the method to get the recirculated gas flow rate from the local gas holdup in the aerated stirred vessel.

The bubbles tend to rise upwards through the

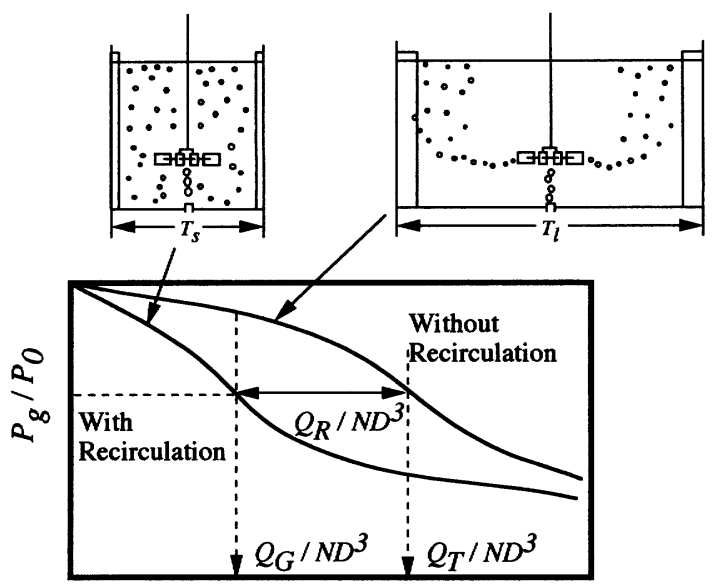

Gas Flow Number, $N_{Q}$

Fig. 6 Estimation of recirculating gas flow rate from power data (van't Riet et al., 1976)

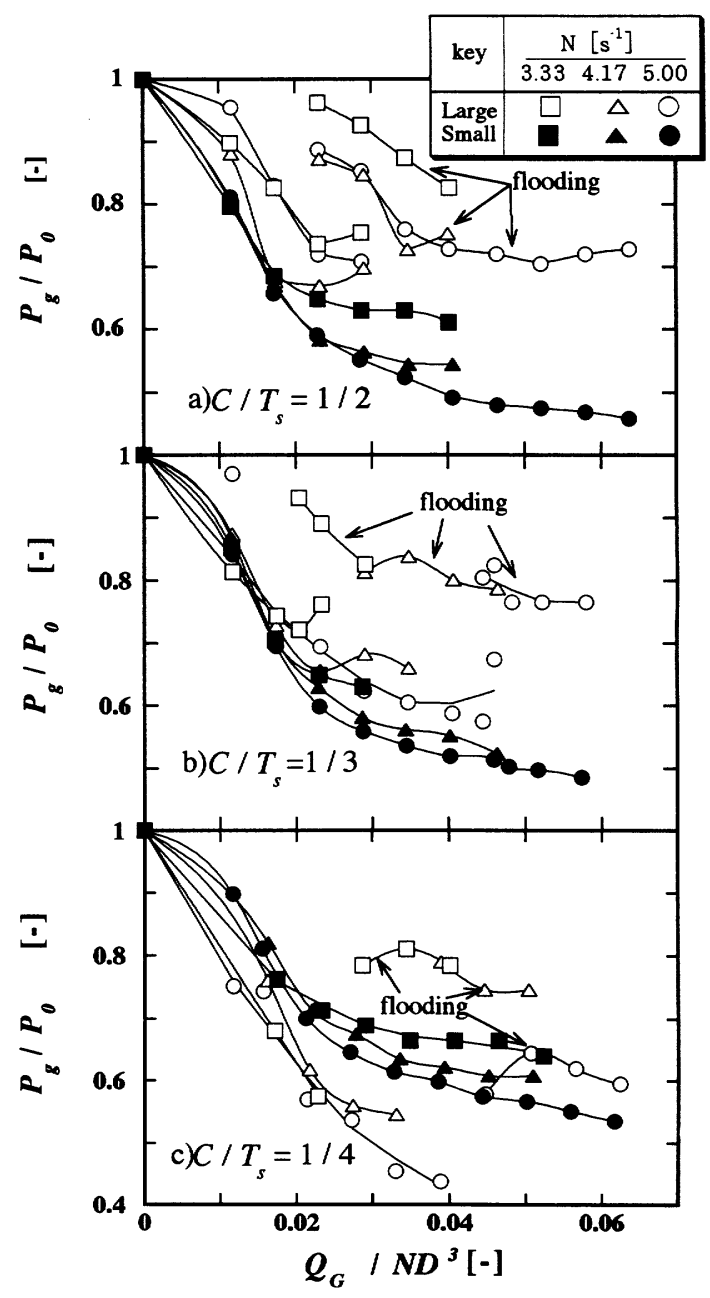

Fig. 7 Power curves for Rushton turbine in large and standard vessels 
vessel due to the difference in gas and liquid density. Therefore, it is difficult for the gas in the upper circulation region to return to the impeller region. That is, no recirculation, except for very small bubbles. On the other hand, the gas bubbles dispersed into the lower circulated region definitely rise and reach the height of the impeller again, except for large bubbles. Thus, most of the recirculated gas consists of bubbles dispersed to the region lower than the impeller. Therefore, the recirculated gas flow rates $Q_{R}$ were calculated from the local gas holdup data in the lower region of the vessel when the bubbles dispersed into the lower circulated region are relatively small.

The amount of recirculated gas $V_{R}\left[\mathrm{~m}^{3}\right]$ was expressed as

$$
V_{R}=\varepsilon_{\text {lower }} \times V_{\text {lower }}
$$

where $\varepsilon_{\text {lower }}$ and $V_{\text {lower }}$ are the gas holdup and the volume in the region lower than the height of impeller, respectively.

The recirculated gas flow rate $Q_{R}$ is given by

$$
R_{Q}=V_{R} / t_{R}
$$

where $t_{R}$ is the time taken by the bubbles to recirculate. Because most bubbles recirculated were considered small ones (Takahashi and Nienow, 1993), we assumed that $t_{R}$ could be represented by the recirculation time of the liquid. The value of $t_{R}$ was determined by measuring time needed for the tracer particle to complete one circuit from the impeller region by using the video camera. The tracer used was a single spherical polystyrene particle of density $0.97 \mathrm{~kg} / \mathrm{m}^{3}$. The experimental conditions were the same as those in measuring gas holdup.

Bruijin et al. (1974) and van't Riet et al. (1976) defined an external distribution coefficient $\alpha$

$$
\alpha=Q_{R} / Q_{G}
$$

and evaluated the recirculated gas flow rate. The results obtained are shown in Fig. 8 with the data obtained by other investigations (van't Riet et al., 1976, Nienow et al., 1977 and Nienow and Chapman, 1979) previously. The external distribution coefficient $\alpha$ was plotted in ordinate and the aeration number in abscissa. The present work agrees well with the previous data. The correlation for $Q_{R}$ obtained is written as follows:

$$
Q_{R}=2.24 \times 10^{-6} N^{4.26} Q_{G}^{0.306}
$$

When recirculation occurs, the freshly sparged gas and the recirculated gas must both pass through the impeller cavities. Thus the overall gas flow rate should

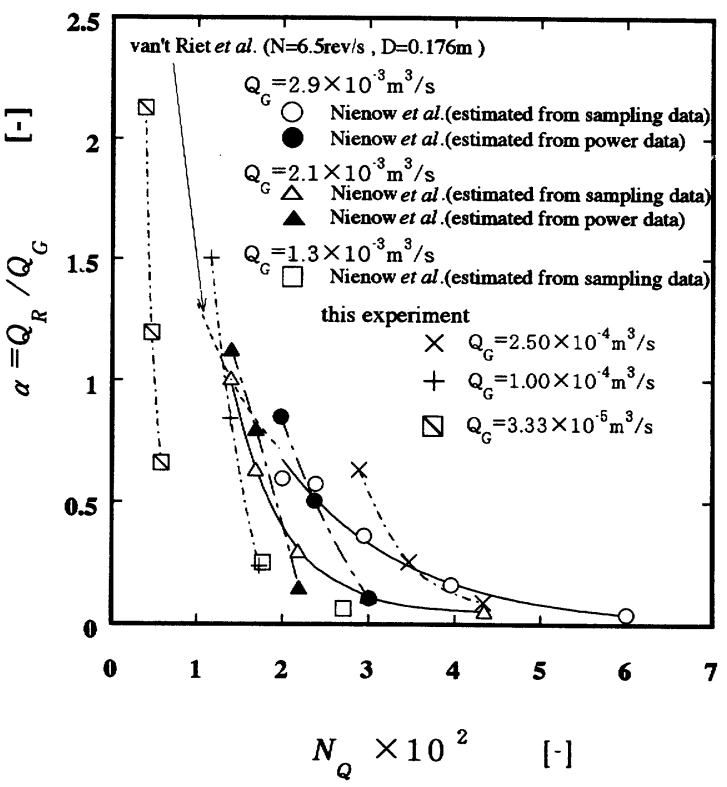

Fig. 8 External distribution coefficient

control the characteristics of gas-liquid mixing. As an example, we tried to correlate the overall gas holdup obtained in this work with the overall gas flow rate. The correlation derived is given by

$$
\varepsilon_{\text {overall }}=2.87 \times 10^{4} N^{-2.12}\left(Q_{G}+Q_{R}\right)^{1.30}
$$

The calculated values are also summarized in Table 1 and the average deviation is $1.55 \times 10^{-3}$, which is significantly lower than that obtained for Eq. (1), even though this correlation overestimates at higher gas inflow rates because hardly any large bubbles dispersed into the lower circulated region return to the impeller region.

\section{Conclusion}

Local gas holdup throughout a vessel equipped with a Rushton turbine impeller was investigated. A complicated distribution of gas holdup was obtained, which could be explained by considering the observed gas dispersion. By integrating the local gas holdup data, the overall gas holdup was determined and correlated with experimental conditions. The recirculated gas flow rate was also obtained by integration of the local gas holdup in the regions lower than the height of impeller. It is suggested that a more precise correlation for the overall gas holdup could be obtained by taking the recirculated gas flow rate into account.

\section{Acknowledgment}

The authors acknowledge the kindness of Satake Chemical Equipment MFG. Ltd. for permission to do some experiments for 
estimation of the recirculated gas flow rate according to the method proposed by van't Riet et al. (1976) in their laboratory.

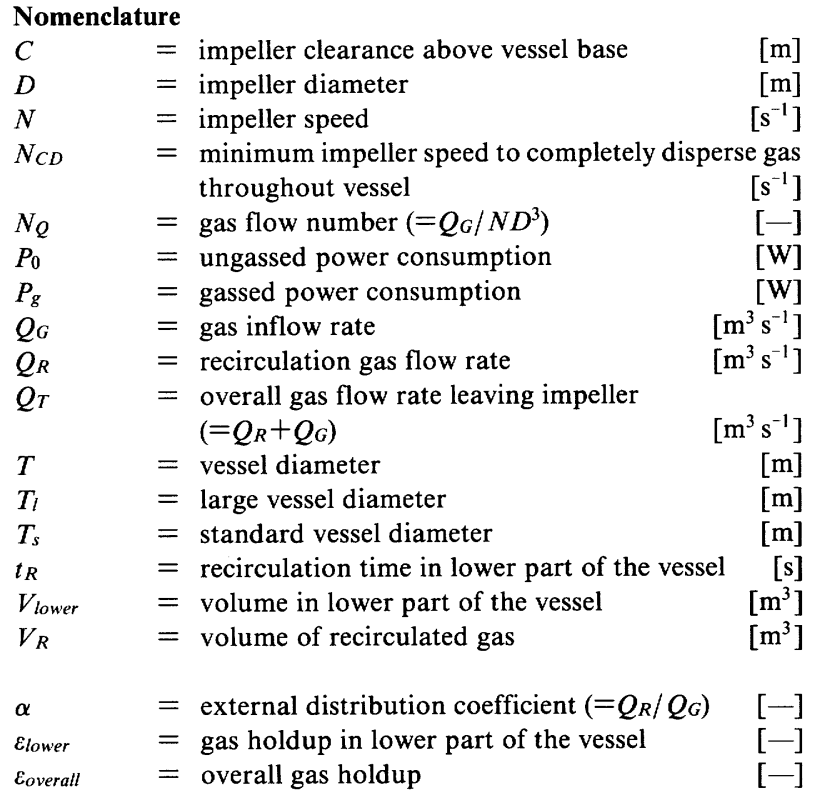

Literature Cited

Bruijn, W., K. van't Riet, and J. M. Smith: "Power Consumption with Aerated Rushton Turbines," Trans. Inst. Chem. Engrs., 52, 88-104 (1976)
Chapman, C. M., A. W. Nienow, M. Cooke and J. C. Middleton: "Particle-Gas-Liquid Mixing in Stirred Vessels Part II: GasLiquid MIxing," Chem. Eng. Res. Des., 61, 82-95 (1983)

Greaves, M. and K. A. H. Kobbacy: "Measurement of Bubble Size Distribution in Turbulent Gas-Liquid Dispersions," Chem. Eng. Res. Des., 62, 3-12 (1984)

Greaves, M. and M. Barigou: "Estimation of Gas Hold-up and Impeller Power in a Stirred Vessel Reactor," Fluid Mixing, I. Chem. Eng.Sym. Ser., No. 108, 235-255 (1988)

Nagase, Y. and H. Yasui: "Fluid Motion and Mixing in a GasLiquid Contactor with Turbine Agitators," Chem. Eng. J., 27, 37-47 (1983)

Nienow, A. W. and C. M. Chapman: "Gas Recirculation Rate through Impeller Cavities and Surface Aeration in Sparged Agitated Vessel," Chem. Eng. J., 17, 111-118 (1979)

Nienow, A. W., D. J. Wisdom and J. C. Middleton: "Effect of Scale and Geometry on Flooding, Recirculation and Power in Gassed Stirred Vessels," 2nd Euro. Conf. Mixing, Cambridge, England, F1, 1-16 (1977)

Smith, J. M. and M. M. C. G. Warmoeskerken: "The Dispersion of Gases in Liquids with Turbines," 5th Euro. Conf. Mixing, Wurzburg, West Germany, Paper 13, 115-126 (1985)

Takahashi, K. and A. W. Nienow: "Bubble Sizes and Coalescence Rates in an Aerated Vessel Agitated by a Rushton Turbine," $J$. Chem. Eng. Japan, 26, 536-542 (1993)

van't Riet, K., J. M. Boom, and J. M. Smith: "Power Consumption, Impeller Coalescence and Recirculation in Aerated Vessels," Trans. Inst. Chem. Engrs., 54, 124-131 (1976) 